\title{
Analysis of Composition and Stability of Emulsions Containing Carotenoids with High Performance Liquid Chromatography (HPLC)
}

\author{
Joanna Igielska-Kalwat* \\ College of Health and Beauty Education, Poland
}

Received: 跙: December 21, 2018; Published: 制: January 11, 2019

*Corresponding author: Joanna Igielska-Kalwat, College of Health and Beauty Education, Brzezinski 3, 60-101 Poznan, Poland

\begin{abstract}
Chromatography is an analytic method utilising the differences between various ingredients of the analysed sample, in the gaseous or liquid phase. One type of liquid chromatography is HPLC (High Performance Liquid Chromatography), a universal analytical method utilised mainly in analysis of complex samples with non-volatile compounds, especially biologically active substances. In cosmetic formulations, the analysis of carotenoid content have been conducted in line with European standards: PN-EN 12823-2 (Foodstuffs - Determination of vitamin A by High Performance Liquid Chromatography) as well as the PN-90 A-75101/12 (Processed fruit and vegetable products. Preparation of samples and methods of physicochemical analysis. Measurements of carotenoid and beta-carotene content). The above methods have been appropriately modified to determine the $\beta$-carotene content in cosmetic preparations.
\end{abstract}

Keywords: $\beta$-Carotene; Lycopene; High Performance Chromatography; Emulsion Stability

\section{Introduction}

Chromatography is an analytic method utilising the differences between various ingredients of the analysed sample, in the gaseous or liquid phase. There is a differentiation between gas and liquid chromatography [1-3]. Liquid chromatography makes use of chromatographic separation effect with liquid used as the mobile phase. The selection of liquid phase composition and stationary phase type depends on the composition of analysed samples [1-3].

One type of liquid chromatography is HPLC (High Performance Liquid Chromatography), a universal analytical method utilised mainly in analysis of complex samples with non-volatile compounds, especially biologically active substances [1-7]. By rule, determination of mixture composition involves the necessity to separate the mixture into individual substances or their groups. It is then possible to establish the amount of the analysed substance in the sample or perform quantitative analysis (determination). The establishment of correlations between the detector's signal and the concentration or mass of the ingredient flowing through the detector's measuring vessel allows for calibration.
In cosmetic formulations, the analysis of carotenoid content have been conducted in line with European standards: PN-EN 12823-2 (Foodstuffs - Determination of vitamin A by High Performance Liquid Chromatography) as well as the PN-90 A-75101/12 (Processed fruit and vegetable products. Preparation of samples and methods of physico-chemical analysis. Measurements of carotenoid and beta-carotene content). The first carotenoid synthesis led to development of methods to determine their content in foodstuffs. For such determinations, various techniques are currently used: Thin Liquid Chromatography (TLC), ultraviolet-visible spectrophotometry and high performance liquid chromatography which is also used in this doctoral dissertation. In 1971, Stewart and Wheaton introduced the above method as a means for determination of carotenoids. They analysed carotenoid amounts in citrus extracts.

\section{Materials and Methods \\ Chemicals and Reagents}

Commercial cosmetics (Tables 1\&2) containing the following carotenoids: $\beta$-carotene oraz lycopene were used in the experiment. 
Table 1: Commercial formulations containing $\beta$-carotene.

\begin{tabular}{|c|c|}
\hline Name of the Cosmetic & Type and Functions \\
\hline Commercial cream 1 & Antioxidant cream \\
\hline Commercial cream 2 & Anti-wrinkle cream \\
\hline Commercial cream 3 & Day/night face cream \\
\hline Commercial cream 4 & Body butter \\
\hline Commercial cream 5 & Body balm with $\beta$-carotene for dry skin \\
\hline Commercial cream 6 & $\begin{array}{c}\text { Lifting and illuminating cream removing } \\
\text { signs of stress and fatigue }\end{array}$ \\
\hline Commercial cream 7 & $\begin{array}{c}\text { Energizing cream for men, removing } \\
\text { signs of fatigue }\end{array}$ \\
\hline Commercial cream 8 & $\begin{array}{c}\text { Cream for sensitive, atopic and } \\
\text { dehydrated skin }\end{array}$ \\
\hline Commercial cream 9 & $\begin{array}{c}\text { Anti-aging, nutritious, revitalizing and } \\
\text { illuminating cream }\end{array}$ \\
\hline Commercial cream 10 & Rejuvenating anti-wrinkle cream, 45+ \\
\hline
\end{tabular}

Table 2: Commercial formulations containing lycopene.

\begin{tabular}{|c|c|}
\hline Name of the Cosmetic & Type and Functions \\
\hline Commercial cream 1 & Strengthening cream \\
\hline Commercial cream 2 & Anti-wrinkle eye cream \\
\hline Commercial cream 3 & Anti-aging day and night cream \\
\hline
\end{tabular}

\section{Autonomously Prepared Cosmetic Emulsions}

The analysis also involved autonomously prepared cosmetic emulsions: $\mathrm{O} / \mathrm{W}, \mathrm{W} / \mathrm{O}$ and $\mathrm{O} / \mathrm{W}$ cold emulsion.

\section{Preparation of $0 / \mathrm{W}$ Creams}

Table 3: Ingredients of $\mathrm{O} / \mathrm{W}$ creams.

\begin{tabular}{|c|c|}
\hline Ingredients & Content $[\mathbf{\%} \pm \mathbf{0 . 0 0 1}]$ \\
\hline Sunflower oil & 12,60 \\
\hline Glycerol monostearate & 3,890 \\
\hline Cetyl alcohol & 5,820 \\
\hline Distilled water & 77,664 \\
\hline $\begin{array}{c}\text { Carotenoids: } \beta \text {-carotene } \\
\text { Lycopene }\end{array}$ & 0,006 \\
\hline
\end{tabular}

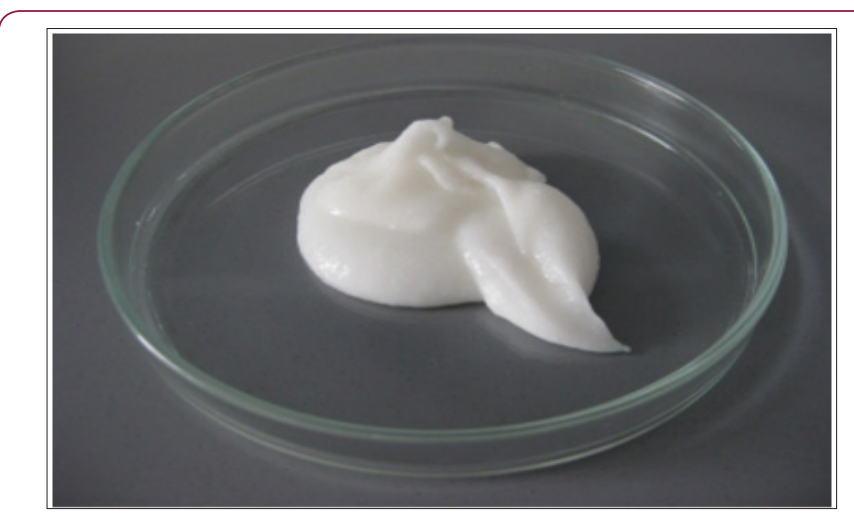

Figure 1: The O/W Cream.

In a $25 \mathrm{ml}$ beaker, the oil phase was prepared by weighing $6.499 \mathrm{~g}$ of sunflower oil, $2.997 \mathrm{~g}$ cetyl alcohol and $2.003 \mathrm{~g}$ of glycerol monostearate (Table 3). In another, $50 \mathrm{ml}$ beaker 40.000 g distilled water were weighed. The oil phase was warmed up to $70^{\circ} \mathrm{C}$ in the water bath until all ingredients melted. The water phase was warmed up to ca. $70^{\circ} \mathrm{C}$ in the water bath and then transferred to a magnetic mixer. While the water phase was being intensively mixed, the oil phase was gradually added in small batches. It was left in the mixer until cool. Further, the appropriate carotenoid was added and mixed in for five minutes. A light consistency cream was obtained (Figure 1).

\section{Preparation of $\mathrm{W} / 0$ Creams}

The oil ingredients: lanolin, sunflower oil, beeswax and cetyl alcohol were warmed up to $70^{\circ} \mathrm{C}$ (Table 4). Simultaneously, the distilled water was warmed up to the same temperature as the oil phase. After complete dissolution of the oil phase ingredients, the water was added; all the while the components were actively being mixed in a magnetic mixer. Further, the appropriate carotenoid was added and mixed in for five minutes. A cream was obtained as in Figure 2.

Table 4: Ingredients of W/O creams.

\begin{tabular}{|c|c|}
\hline Ingredients & Content $[\% \pm 0.001]$ \\
\hline Lanolin & 10,210 \\
\hline Sunflower oil & 39,900 \\
\hline Beeswax & 4,990 \\
\hline Cetyl alcohol & 4,990 \\
\hline Distilled water & 39,904 \\
\hline $\begin{array}{c}\text { Carotenoids: } \beta \text {-carotene } \\
\text { Lycopene }\end{array}$ & 0,006 \\
\hline
\end{tabular}

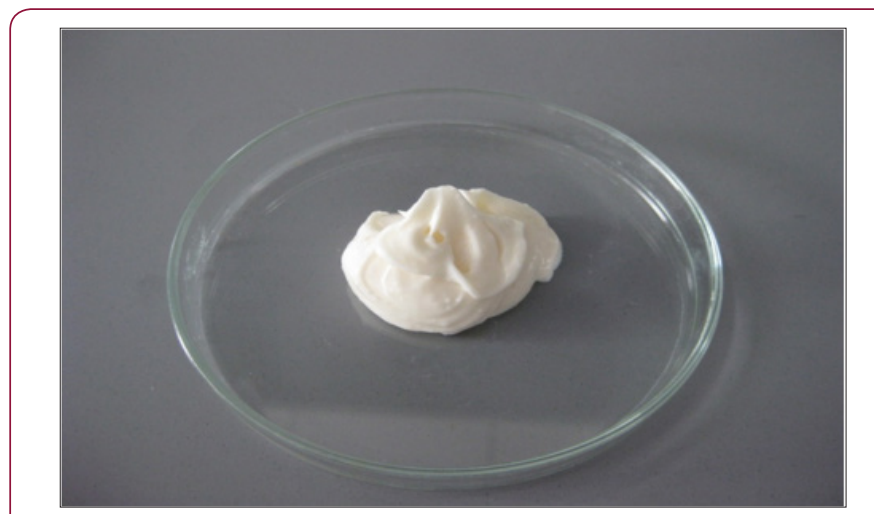

Figure 2: The W/O Cream.

\section{Preparation of $0 / \mathrm{W}$ Cold Creams}

In a $50 \mathrm{ml}$ beaker, $5.000 \mathrm{~g}$ of Creagel and $8.500 \mathrm{~g}$ of Alpha flow were weighed (Table 5). In a second $50 \mathrm{ml}$ beaker, 36.5497 $\mathrm{g}$ of distilled water were weighed. The contents of the first beaker were thoroughly mixed in a magnetic mixer at room temperature. Distilled water was added in small portions during the continuous mixing. Further, the appropriate carotenoid was added and mixed in for minutes. A thick cream of white colour was obtained (Figure 3). 
Table 5: Ingredients of $\mathrm{O} / \mathrm{W}$ cold creams.

\begin{tabular}{|c|c|}
\hline Ingredients & Content $[\% \pm 0.001]$ \\
\hline $\begin{array}{l}\text { Creagel EZ7 -hydrogenated } \\
\text { polydecene, }\end{array}$ & 10,210 \\
\hline polyoxyethylene lauryl ether & 10,000 \\
\hline $\begin{array}{c}\text { Alpha flow 20-hydrogenated } \\
\text { polydecene }\end{array}$ & 17,000 \\
\hline Distilled water & 72,994 \\
\hline $\begin{array}{c}\text { Carotenoids: } \beta \text {-carotene } \\
\text { Lycopene }\end{array}$ & 0,006 \\
\hline $\begin{array}{c}\text { Carotenoids: } \beta \text {-carotene } \\
\text { Lycopene }\end{array}$ & 0,006 \\
\hline
\end{tabular}

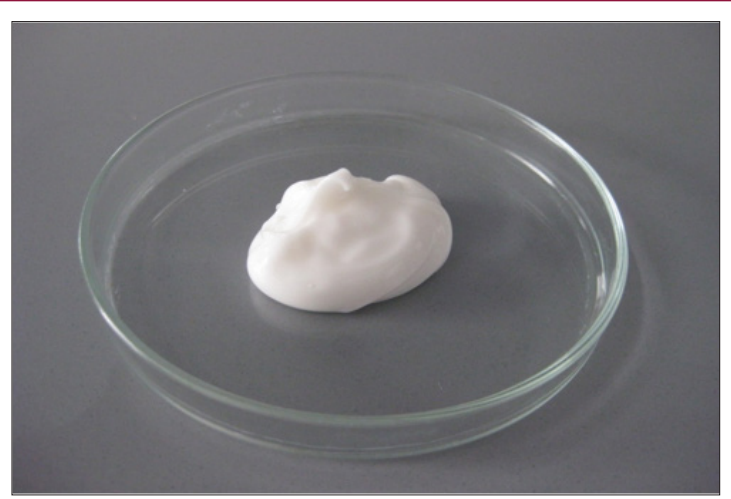

Figure 3: The O/W Cold cream.

\section{Determination of $\beta$-Carotene}

Table 6: Conditions for determination of $\beta$-carotene content in commercial creams with high performance liquid chromatography.

\begin{tabular}{|c|c|c|c|}
\hline \multicolumn{4}{|c|}{ Measurement Conditions } \\
\hline Chromatographic column & \multicolumn{3}{|c|}{ Zorbax SB-C18 } \\
\hline$(250 \times 4.6 \mathrm{~mm} ; 5.0 \mu \mathrm{m})$ & \multicolumn{3}{|c|}{10,000} \\
\hline Mobile phase & \multicolumn{3}{|c|}{ A: methanol: water $(80: 20 \mathrm{v} / \mathrm{v})$} \\
\hline B: ethyl acetate & \multicolumn{3}{|c|}{72,994} \\
\hline Mobile phase flow velocity & \multicolumn{3}{|c|}{$1 \mathrm{ml} / \mathrm{min}$} \\
\hline $\begin{array}{l}\text { Length of UV-Vis wave at } \\
\text { detection }\end{array}$ & \multicolumn{3}{|c|}{$\lambda=450 \mathrm{~nm}$} \\
\hline Volume of the samples & \multicolumn{3}{|c|}{$10 \mu \mathrm{l}$} \\
\hline \multirow{6}{*}{ Gradient Elution } & Time [min] & A [\%] & B [\%] \\
\hline & 0,0 & 80,0 & 20,0 \\
\hline & 2.5 & 77,5 & 22,5 \\
\hline & 20,0 & 50,0 & 50,0 \\
\hline & 24,0 & 20,0 & 80,0 \\
\hline & 31,0 & 0,0 & 100,0 \\
\hline Analysis time & \multicolumn{3}{|c|}{$31 \mathrm{~min}$} \\
\hline
\end{tabular}

In the study, determination of $\beta$-carotene content in commercial creams with use of HPLC has been conducted according to standards for determination of carotenoid content in foodstuffs: PN-EN 12823-2 (Foodstuffs - Determination of vitamin A by High Performance Liquid Chromatography) as well as the PN-90
A-75101/12 (Processed fruit and vegetable products. Preparation of samples and methods of physico-chemical analysis. Measurements of carotenoid and beta-carotene content). The above methods have been appropriately modified to determine the $\beta$-carotene content in cosmetic preparations [8-11]. For quantitative determination of $\beta$-carotene in universally available cosmetic creams, the Varian 920LC liquid chromatograph was used. Table 6 presents conditions for determination of $\beta$-carotene content in commercial creams.

Preparation of the sample for tests consisted in: Homogenisation of the cream; saponification under reflux conditions with $1 \mathrm{~g}$ of ascorbic acid, $30 \mathrm{ml}$ of alcoholic solution of potassium hydroxide; extraction with $10 \mathrm{ml}$ of $\mathrm{n}$-hexane. The standard solution was prepared by weighing $5 \mathrm{mg}$ of $\beta$-carotene and dissolving it in a 5 $\mathrm{ml}$ flask with the mobile phase. Further, a series of dilutions was performed: 2, 4, 8, 10 and $16 \mu \mathrm{g} / \mathrm{ml}$. The flask was placed in an ultrasonic bath for complete dissolution of $\beta$-carotene. At the first stage of the study the calibration curve was drawn for $\beta$-carotene. It served as a basis for determination of this active substance in cosmetic formulations. Identification of carotenoids in actual samples was performed after comparison of retention time of samples with retention time of standards.

Based on the peak areas of $\beta$-carotene obtained in chromatograms, the mass concentration of $\beta$-carotene in cosmetic preparations was calculated.

In the calculations, the following formula was used:

$$
C=\frac{A_{x \cdot C_{s} \cdot v}}{A_{s} \cdot P}
$$

where:s

Ax - Peak area obtained for sample solution in the test, in area units [mAU·min]

Cs - Concentration of the standard solution of known purity $[\mu \mathrm{g} / \mathrm{ml}]$

$\mathrm{V}$ - Total volume of sample solution in the test [ml]

As - peak area obtained for standard solution in the test, in area units [mAU·min]

$$
\mathrm{P} \text { - sample mass }[\mathrm{g}]
$$

\section{Determination of Lycopene}

Table 7: Conditions for determination of lycopene content in commercial creams with high performance liquid chromatography.

\begin{tabular}{|c|c|}
\hline \multicolumn{2}{|c|}{ Chromatographic Column } \\
\hline Mobile phase & $\begin{array}{c}\text { A: acetonitrile: dichloromethane: } \\
\text { methanol }(70: 20: 10 \mathrm{v} / \mathrm{v})\end{array}$ \\
\hline Mobile phase flow velocity & $1 \mathrm{ml} / \mathrm{min}$ \\
\hline Length of UV-Vis wave at detection & $\lambda=472 \mathrm{~nm}$ \\
\hline Volume of the samples & $10 \mu \mathrm{l}$ \\
\hline Analysis time & $10 \mathrm{~min}$ \\
\hline Chromatographic column & Zorbax SB- C18 $(250 \times 4.6 \mathrm{~mm} ;$ \\
$5.0 \mu \mathrm{m})$
\end{tabular}


The abovementioned standards, methodology and apparatus have been applied in the study to determine lycopene in commercial creams with HPLC. Detailed conditions for the measurement are presented in table 7 .

Preparation of the sample for the test was presented in section 4.3.1. The sample solution was prepared by weighing $5 \mathrm{mg}$ of lycopene and dissolving it in $5 \mathrm{ml}$ of the mobile phase. Further, a series of dilutions was performed: 2, 4, 8, 10 and $16 \mu \mathrm{g} / \mathrm{ml}$. The flask was placed in an ultrasonic bath for complete dissolution of lycopene. Calculations were performed with the formula presented above.

\section{Determination of Stability of $\beta$-Carotene and Lycopene Contained in Autonomously Prepared Cosmetic Formulations}

The abovementioned standards, methodology and apparatus have been applied in the study to determine stability of $\beta$-karotenu in autonomously prepared cosmetic formulations $(\mathrm{O} / \mathrm{W}, \mathrm{W} / \mathrm{O}$ and cold $\mathrm{O} / \mathrm{W}$ ). The emulsions were tested immediately after preparation, after one week, two weeks, one month, two months and three months. Changes of carotenoid content in time were compared with appropriately prepared initial sample with known $\beta$-carotene and lycopene content $(6 \mathrm{mg} / 100 \mathrm{~g}$ ). Identification of carotenoids in actual samples was performed after comparison of retention time of samples with retention time of standards. Calculations were performed with the formula presented earlier.

\section{Results and Discussion}

The methodology for determination of carotenoids in cosmetic creams has been developed on the basis of available literature concerning foodstuffs. Various solvents were tested for the mobile phase in various proportions. The following parameters were modified: flow velocity of the mobile phase, wave length of the UVVis detector during the test, volume of tested samples and analysis time. Gradient and isocratic elutions were tested. In the course of conducted experiments, the effectiveness of the extraction method amounted to $90.56 \%$. The Limit of Quantification (LOQ) stood at $1.04 \mu \mathrm{g} / \mathrm{ml}$ (Figure 4).

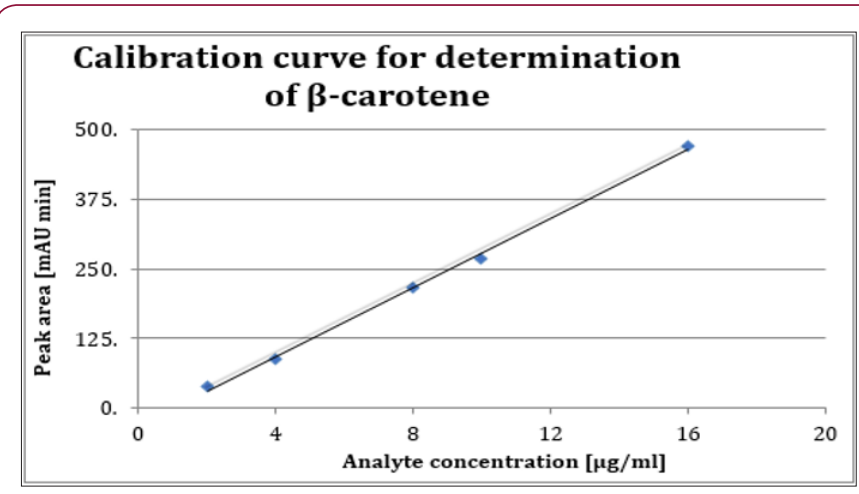

Figure 4: Calibration curve for determination of $\beta$-carotene.

Illustration 4 presents the calibration curve for determination of $\beta$-carotene dissolved in the solvent (mobile phase: A: methanol: water (80:20 v/v, B: ethyl acetate). This method of determination is characterised by wide linearity with correct correlation coefficient, R2 $=0.998$. The chromatograms (Figure 5) show peaks of $\beta$-carotene introduced to the dispenser of the HPLC device at various concentrations, with the retention time of ca. 27 minutes.

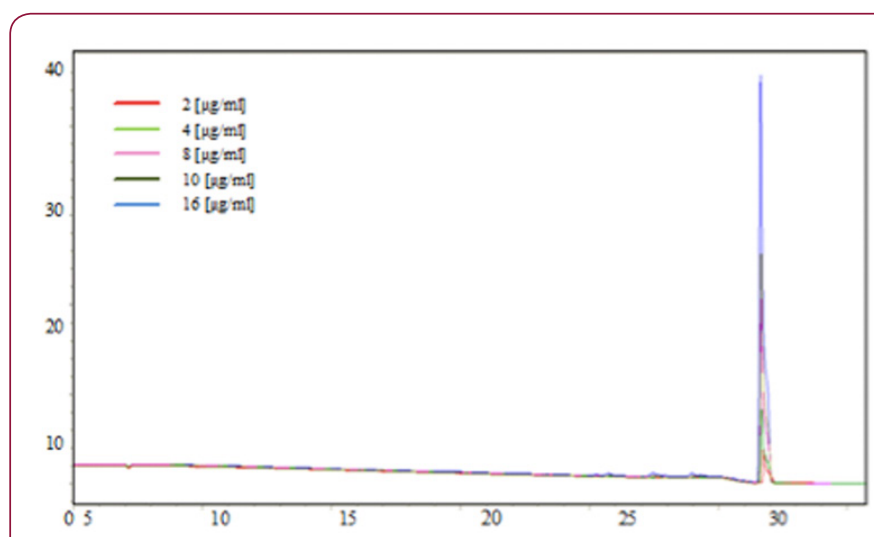

Figure 5: Chromatograms of standard $\beta$-carotene solutions at various concentrations.

The study involved emulsions containing carotenoids. Identification of analysed compounds was conducted by comparing their retention Time Values (tR) with appropriate standards and by spectrophotometer analysis of absorption spectrums. The HPLC analysis of commercial creams claimed to contain $\beta$-carotene confirmed the presence of this ingredient. Table 8 presents the mass fraction of $\beta$-carotene concentration contained in $100 \mathrm{mg}$ of commercial creams. The amount of $\beta$-carotene measured in those creams ranges from 3.10 to $10.45 \mathrm{mg} / 100 \mathrm{~g}$ of the formulation. The highest carotenoid content was found in Commercial cream 4, and the lowest in Commercial cream 2 preparation. Following the analyses, the $\beta$-carotene content declared by the manufacturers according to the INCI was analysed. Cosmetic corporations produce cosmetics with $\beta$-carotene since the compound is one of the most powerful anti-oxidants. Its molecules do not regenerate as it is with other anti-oxidants. Rather, there are undergo degradation as they neutralise free radicals, the reactive forms of oxygen. Therefore, increasing the level of carotenoids in the skin boosts its regeneration and delays aging [12-14].

Table 8: Mass fraction of $\beta$-carotene in commercial creams.

\begin{tabular}{|c|c|}
\hline Cream Name & $\begin{array}{r}\boldsymbol{\beta} \text {-carotene Content [mg] [ } \mathbf{0 . 0 5} \\
\text { in 100 g of preparation }\end{array}$ \\
\hline Commercial cream 4 & 3,10 \\
\hline Commercial cream 9 & 3,43 \\
\hline Commercial cream 6 & 3,50 \\
\hline Commercial cream 3 & 4,29 \\
\hline Commercial cream 10 & 5,30 \\
\hline Commercial cream 1 & 5,58 \\
\hline Commercial cream 7 & 6,30 \\
\hline Commercial cream 5 & 7,80 \\
\hline Commercial cream 8 & 9,24 \\
\hline Commercial cream 2 & 10,45 \\
\hline
\end{tabular}




\section{Determination of Lycopene}

Following the analysis performed with high performance liquid chromatography, the calibration curve of lycopene was drawn (Figure 6). The curve confirms wide linearity of the applied method, with the correlation coefficient maintained at 0.997 . In the course of conducted experiments, the effectiveness of the extraction method amounted to $88.66 \%$. The Limit of Quantification (LOQ) stood at $0.94 \mu \mathrm{g} / \mathrm{ml}$. Illustration 6 presents the calibration curve for determination of $\beta$-carotene dissolved in the solvent (mobile phase: acetonitrile: dichloromethane: methanol $(70: 20: 10 \mathrm{v} / \mathrm{v}))$. Chromatograms identify peaks related to lycopene (Figure 7), with the retention time of ca. 8.3 minutes.

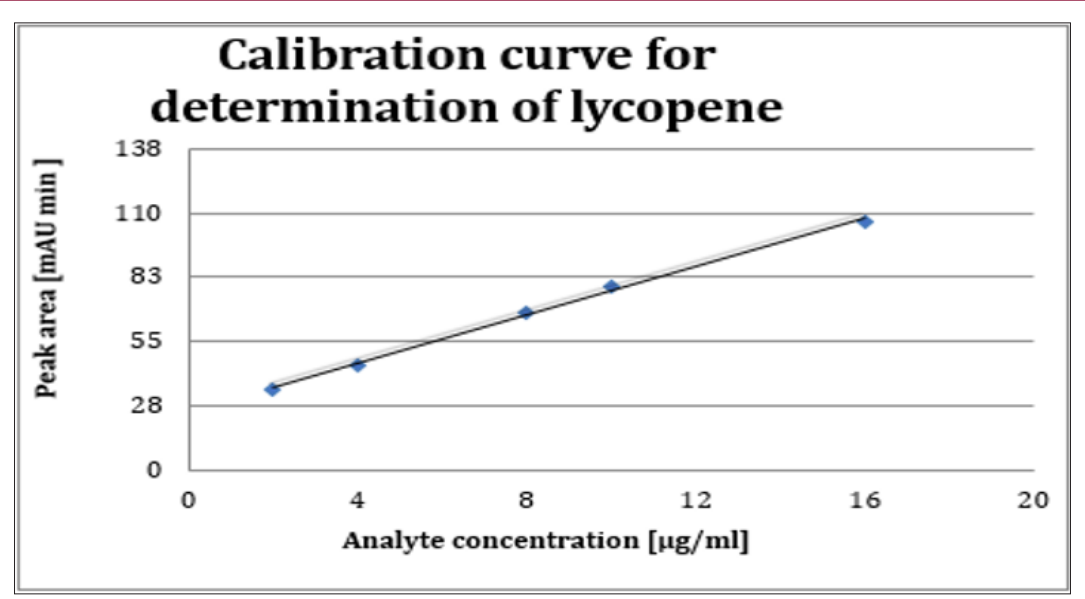

Figure 6: Calibration curve for determination of lycopene.

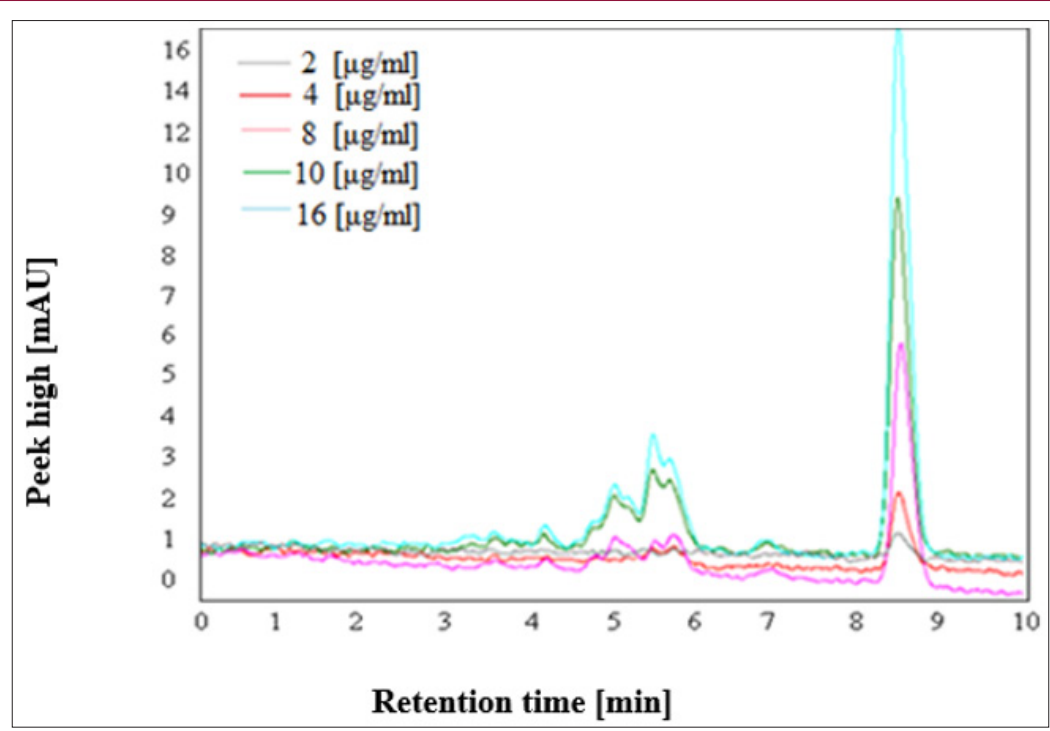

Figure 7: Chromatograms of standard solutions of lycopene at various concentrations.

Tests aiming at confirmation of lycopene content in commercial creams were conducted with use of high performance liquid chromatography. The analyses have confirmed the presence of this carotenoid in emulsions, as declared by the manufacturers. The values of retention times ( $\mathrm{tr}$ ) and absorption spectrums were compared. The amount of lycopene measured in creams included in Table 9 ranged from 3.53 to $6.57 \mathrm{mg} / 100 \mathrm{~g}$ of the formulation. The Commercial cream 1 included the highest amount of lycopene, while the Commercial cream 3 the lowest. All lycopene-containing cosmeting are anti-aging emulsions. The aim of these formulations is to delay the aging of the sin. Due to the anti-oxidant characteristics, lycopene fulfils this aim and hence is often used by manufacturers of such cosmetics.
Table 9: Mass fraction of lycopene contained in tested commercial creams.

\begin{tabular}{|c|c|}
\hline Cream Name & $\begin{array}{c}\text { Lycopene Content [mg] in 100 g } \\
\text { of Formulation [ [ } \mathbf{\pm 0 . 0 5}]\end{array}$ \\
\hline Commercial cream 1 & 3,53 \\
\hline Commercial cream 2 & 4,04 \\
\hline Commercial cream 3 & 6,57 \\
\hline
\end{tabular}

Determination of Stability of $\beta$-Carotene and Lycopene Contained in Autonomously Prepared Cosmetic Formulations

The stability was determined for three types of emulsions: cold $\mathrm{O} / \mathrm{W}$ emulsion, hot $\mathrm{O} / \mathrm{W}$ emulsion and $\mathrm{W} / 0$ emulsion. All were 
stored in differing conditions. Cosmetic formulations containing $\beta$-carotene. As may be concluded from the analyses, the amount of determined $\beta$-carotene decreases in all types of emulsions already after one week of storage in various conditions (Figure 8) and (Table 10). The compound destabilises the fastest at the temperature of $45^{\circ} \mathrm{C}$, and the slowest at room temperature under dark conditions.
Table 10 presents the percentage loss of $\beta$-carotene divided into particular weeks. Due to the presence of double bonds, carotenoids undergo oxidation easily. In case of $\beta$-carotene, oxidation by molecular oxygen and high temperature begins with unsaturated bonds in the $\beta$-ionone ring. The process leads to loss of provitamin A properties, isomerisation of the compound and change in colour.
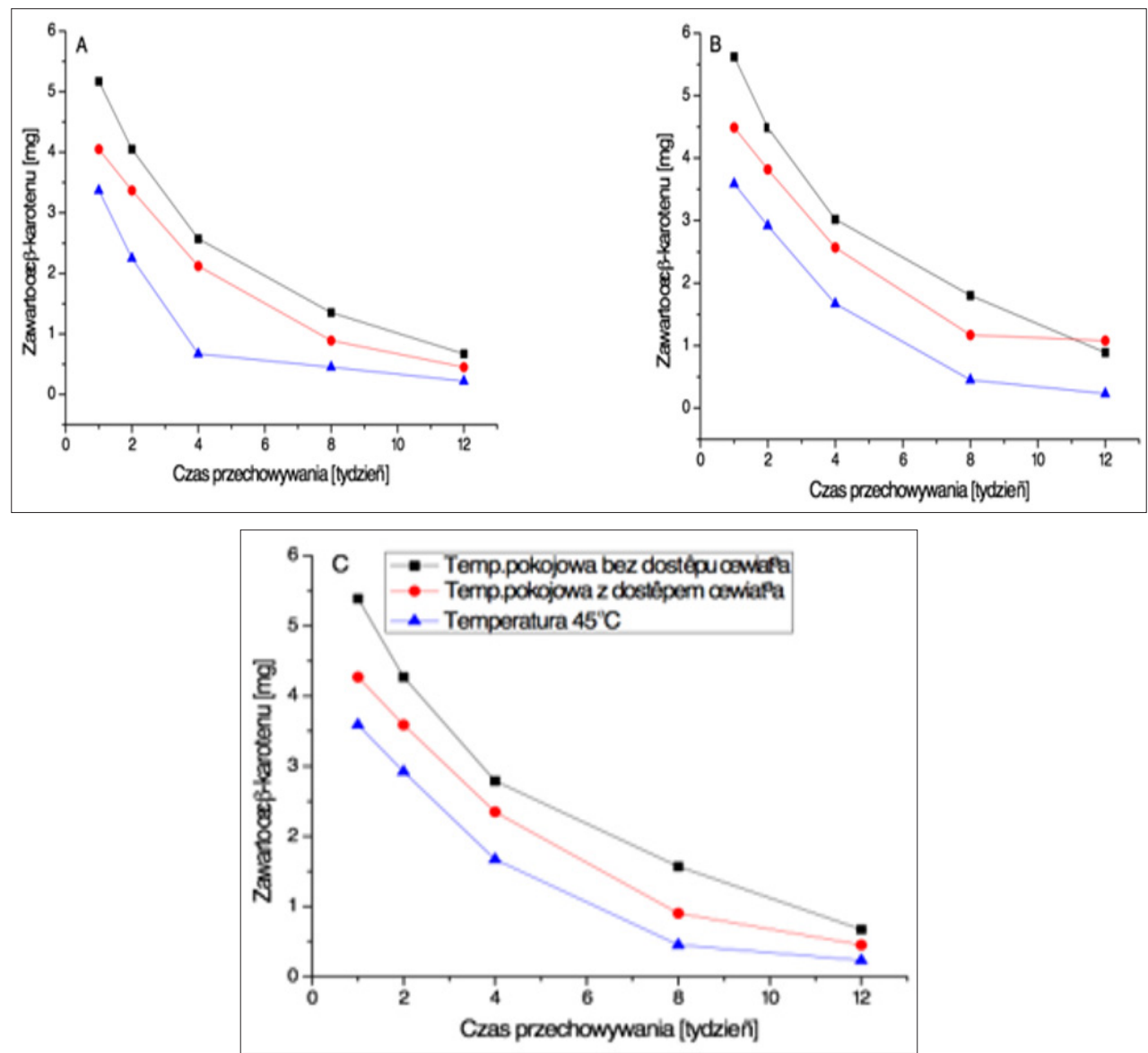

Note: a) Cold O/W Emulsion; b) Hot O/W Emulsion; c) W/O Emulsion.

- Room temperature away from the light.

- Room temperature, in ligh.

$\Delta \quad$ Temperature of $45^{\circ} \mathrm{C}$.

Figure 8: Changes in $\beta$-carotene content (per $100 \mathrm{~g}$ of the sample) depending on the time and conditions for sample storage.

Table 10: Percentage loss of $\beta$-carotene in various types of emulsions, stored for 100 days in various conditions.

a) Cold O/W Emulsion.

\begin{tabular}{|c|c|c|c|}
\hline \multicolumn{3}{|c|}{ Percentage loss of $\boldsymbol{\beta}$-carotene [\%] [ $\mathbf{\pm 0 . 0 1 ]}$} \\
\hline Storage Time [Weeks] & $\begin{array}{c}\text { Room Temperature, Away from The } \\
\text { Light }\end{array}$ & Room temperature, in light & Temperature of \\
\hline 0 & 0 & 0 & 36,96 \\
\hline 1 & 7,26 & 25,91 & 44,39 \\
\hline 2 & 25,91 & 36,96 & 65,02 \\
\hline 4 & 50,17 & 57,60 & 99,56 \\
\hline 12 & 70,30 & 80,69 & 99,77 \\
\hline
\end{tabular}


b) Hot $\mathrm{O} / \mathrm{W}$ Emulsion.

\begin{tabular}{|c|c|c|c|}
\hline \multicolumn{4}{|c|}{ Percentage loss of $\beta$-carotene $[\%][ \pm 0.01]$} \\
\hline Storage Time [Weeks] & $\begin{array}{c}\text { Room Temperature, Away from The } \\
\text { Light }\end{array}$ & Room Temperature, in Light & Temperature of \\
\hline $45^{\circ} \mathrm{C}$ & 0 & 0 & 0 \\
\hline 0 & 0 & 0 & 0 \\
\hline 1 & 14,69 & 33,17 & 44,39 \\
\hline 2 & 33,17 & 44,39 & 62,81 \\
\hline 4 & 57,59 & 65,02 & 88,94 \\
\hline 8 & 77,72 & 85,33 & 92,54 \\
\hline 12 & 88,94 & 92,57 & 96,37 \\
\hline
\end{tabular}

c) W/O Emulsion.

\begin{tabular}{|c|c|c|c|}
\hline \multicolumn{2}{|c|}{ Percentage loss of $\beta$-carotene [\%] [ $\mathbf{0 . 0 1}]$} \\
\hline Storage Time [Weeks] & $\begin{array}{c}\text { Room Temperature, Away from The } \\
\text { Light }\end{array}$ & Room Temperature, in Light & Temperature of \\
\hline $45^{\circ} \mathrm{C}$ & 0 & 0 & 0 \\
\hline 0 & 0 & 0 & 0 \\
\hline 1 & 11,06 & 29,54 & 50,76 \\
\hline 2 & 29,54 & 40,76 & 51,86 \\
\hline 4 & 53,97 & 61,21 & 72,44 \\
\hline 8 & 74,09 & 85,15 & 92,58 \\
\hline 12 & 88,94 & 92,58 & 96,21 \\
\hline
\end{tabular}

The final products of $\beta$-carotene oxidation are often characterised by unpleasant smells. Oxidation of carotenoids follows the influence of radicals. The results of the doctoral study on instability of $\beta$-carotene contained in cosmetic formulations stored in high temperatures and under influence of light and oxygen are in line with observations of scientific publications to date $[15,16]$. The stability of $\beta$-carotene is affected by storage conditions, especially temperature and light access. The higher the storage temperature, the bigger the loss of carotenoid content. $\beta$-carotene is the most stable in cold $\mathrm{O} / \mathrm{W}$ emulsions. Higher carotenoid longevity in this formulation may result from method of preparation of the emulsion. It does not require high temperature, hence the higher stability of $\beta$-carotene.

Table 11: Percentage of lycopene in various types of emulsions stored for 100 days in various conditions.

a) Cold O/W Emulsion.

\begin{tabular}{|c|c|c|c|}
\hline \multicolumn{4}{|c|}{ Percentage loss of lycopene $[\%][ \pm 0.01]$} \\
\hline Storage Time [Weeks] & $\begin{array}{c}\text { Room Temperature, Away from The } \\
\text { Light }\end{array}$ & Room Temperature, in Light & Temperature of \\
\hline $45^{\circ} \mathrm{C}$ & 0 & 0 & 0 \\
\hline 0 & 0 & 0 & 0 \\
\hline 1 & 7,26 & 14,70 & 51,82 \\
\hline 2 & 15,84 & 20,46 & 62,87 \\
\hline 4 & 25,91 & 27,89 & 74,09 \\
\hline 8 & 42,02 & 51,82 & 81,52 \\
\hline 12 & 74,09 & 77,72 & 92,54 \\
\hline
\end{tabular}

b) Hot $\mathrm{O} / \mathrm{W}$ Emulsion.

\section{Percentage loss of lycopene $[\%][ \pm 0.01]$}

\begin{tabular}{|c|c|c|c|}
\hline \multicolumn{3}{|c|}{ Percentage loss of lycopene [\%] [ $\mathbf{0 0 . 0 1 ]}$} \\
\hline Storage Time [Weeks] & $\begin{array}{c}\text { Room Temperature, Away from The } \\
\text { Light }\end{array}$ & Room Temperature, in Light & Temperature of \\
\hline $45^{\circ} \mathrm{C}$ & 0 & 0 & 0 \\
\hline 0 & 0 & 0 & 0 \\
\hline
\end{tabular}




\begin{tabular}{|c|c|c|c|}
\hline 1 & 14,70 & 22,11 & 59,21 \\
\hline 2 & 25,91 & 44,39 & 70,39 \\
\hline 4 & 49,67 & 51,82 & 81,46 \\
\hline 8 & 65,35 & 59,54 & 88,88 \\
\hline
\end{tabular}

c) W/O Emulsion.

Percentage loss of lycopene $[\%][ \pm 0.01]$

\begin{tabular}{|c|c|c|c|}
\hline Storage Time [Weeks] & $\begin{array}{c}\text { Room Temperature, Away from The } \\
\text { Light }\end{array}$ & Room Temperature, in Light & Temperature of \\
\hline $45^{\circ} \mathrm{C}$ & 0 & 0 & 0 \\
\hline 0 & 0 & 0 & 55,45 \\
\hline 1 & 10,06 & 18,49 & 66,67 \\
\hline 2 & 22,12 & 35,81 & 77,72 \\
\hline 4 & 29,54 & 48,18 & 85,31 \\
\hline 8 & 51,82 & 58,75 & 96,21 \\
\hline
\end{tabular}
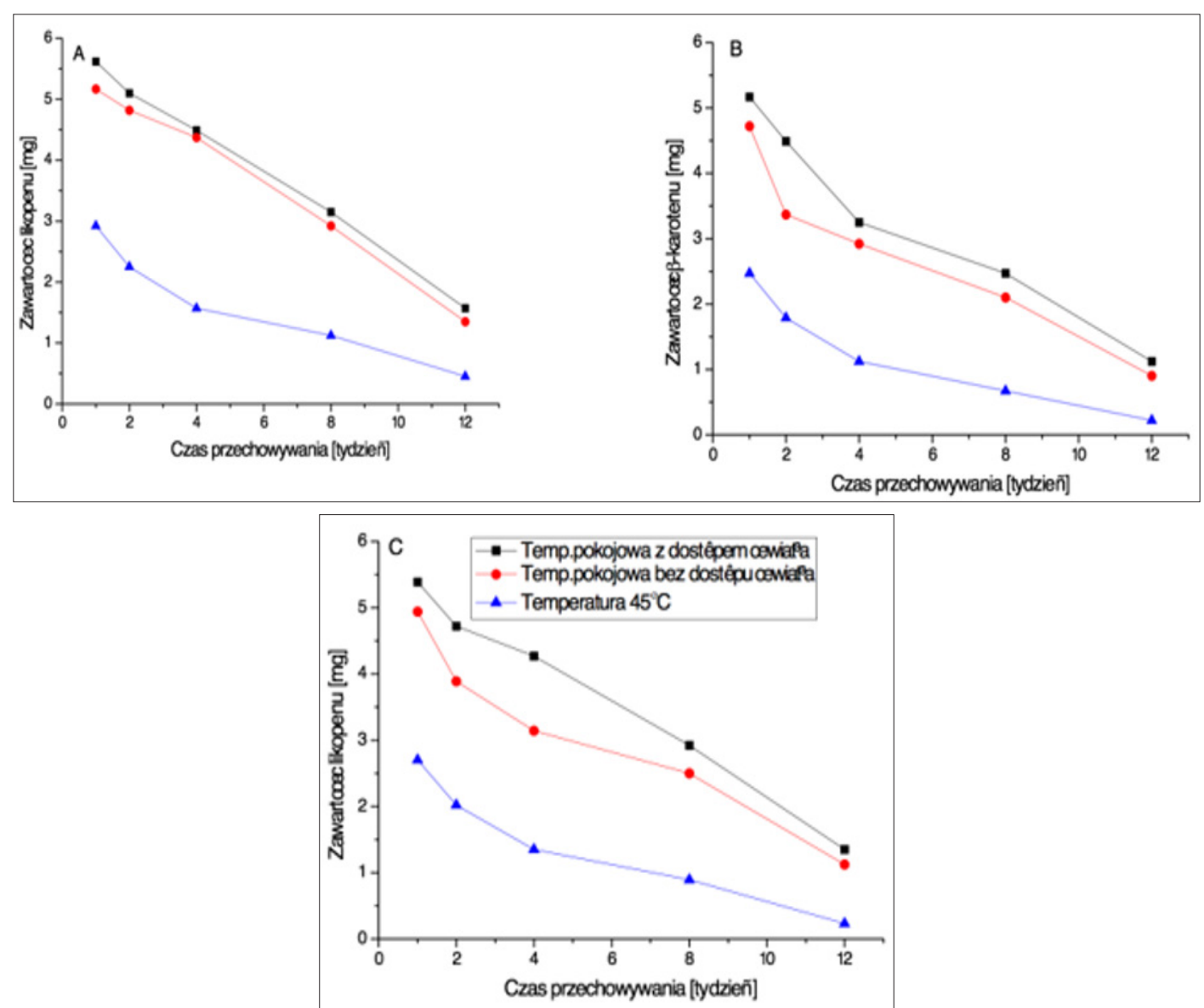

Note: $\otimes$ Room temperature away from the light.

- Room temperature, in light.

$\Delta \quad$ Temperature of $45^{\circ} \mathrm{C}$.

Figure 9: Changes in lycopene content depending on the time and conditions for sample storage. a) Cold O/W Emulsion; b) Hot O/W Emulsion; c) W/O Emulsion.

The stability of lycopene depends on its chemical structure, cosmetic product which contains it, and the environment: mainly temperature, length of the technological process, presence of light,
$\mathrm{pH}$, oxygen and heavy metals. Consideration of these parameters and application of an appropriate technological process guarantee the obtaining of high-quality final product of natural colour. 
Following the analyses of lycopene stability, it may be concluded that it undergoes degradation in the presence of oxygen and at high temperature (Figure 9) [16]. This conclusion had already been drawn by Lee and Chen [17], who established the influence of heat and light on the stability of lycopene. They demonstrated that the degradation of the carotenoid was a first-order reaction both when higher temperature was applied and when the compound was exposed to light at room temperature.

The most common (95\%) form of lycopene is trans form. When exposed to the light and higher temperatures, or due to chemical reactions, it may undergo optical isomerisation to the cis form. Table 11 presents the percentage loss of lycopene in all types of emulsions under the influence of oxygen and the temperature of $45^{\circ} \mathrm{C}$ [18]. The resulting products are large amounts of apo8'-lycopenal, apo-6'-lycopenal and apo-12'-lycopenal as well as smaller amounts of apo-10'-lycopenal and apo-14'-likopenal [19]. The double C15-C15' bond is rarely broken [19].

The non-conjugated double bonds situated near the ends of the molecule do not undergo oxidation. In order to increase the stability of emulsions containing lycopene, it is advised to store the products in dark containers or in the dark [19]. Similarly, to $\beta$-carotene, lycopene is the most stable in cold 0/W emulsions. Carotenoids are characterised by continuing loss of content throughout the study.

\section{Conclusion}

In consequence of the study, an appropriate method for determination of $\beta$-carotene in commercial creams with High Performance Liquid Chromatography (HPLC) was established. It has been shown that the most appropriate mobile phase for determination of the above carotenoid is the following: A: methanol: water $(80: 20 \mathrm{v} / \mathrm{v}), \mathrm{B}$ : ethyl acetate. The mass concentration of $\beta$-carotene contained in analysed commercial creams ranged from 3.10 to $10.45 \mathrm{mg}$ per $100 \mathrm{~g}$. Further, an appropriate method for determination of lycopene in commercial creams with High Performance Liquid Chromatography (HPLC) was also found. In the case of this compound, the most appropriate mobile phase is as follows: acetonitrile: dichloromethane: methanol (70:20:10 $\mathrm{v} / \mathrm{v})$ ). The lycopene content in abovementioned commercial creams ranged from 3.53 to $6.57 \mathrm{mg}$ per $100 \mathrm{~g}$ of the formulation. The analysis confirmed that the storage time in various conditions influences and corresponds to the percentage loss of $\beta$-carotene and lycopene introduced to cosmetic emulsions. Lycopene destabilises the fastest at the temperature of $45^{\circ} \mathrm{C}$, and the slowest at room temperature under dark conditions. The most stable type of emulsion containing $\beta$-carotene and lycopene has been determined as cold $\mathrm{O} / \mathrm{W}$ emulsion.

\section{Acknowledgement}

Financial support from Polish Ministry of Science and Higher Education is acknowledged.

\section{References}

1. Witkiewicz Z (2005) Podstawy chromatografii, WNT, Warszawa.

2. Speek AJ, Temalilwa CR, Schrijver J (1986) Determination of $\beta$-carotene content and vitamin A activity of vegetables by high-performance liquid chromatography and spectrophotometry. J Food Chem 19(1): 65-74.

3. Bushway RJ, Wilson AM (1984) Selected properties of the lipid and protein fractions from chia seed. Food Sci Technol J 49(2): 555-557.

4. Quackenbush FW (1987) J Liq Chrom 10: 643-650.

5. Thomposn JN, Hatina G, Maxwell WB (1980) High performance liquid chromatographic determination of vitamin A in margarine, milk, partially skimmed milk, and skimmed milk. J Assoc Off Anal Chem 63(4): 894- 898.

6. Meléndez-Martínez AJ, Vicario IM, Heredia FJ (2007) Provitamin A carotenoids and ascorbic acid contents of the different types of orange juices marketed in Spain. Food Chem 101: 177-184.

7. Bushway RJ (1985) J Lig Chromatography 8: 1527-1533.

8. PN-EN 12823-2 (Foodstuffs - Determination of vitamin A by High Performance Liquid Chromatography).

9. PN-90 A-75101/12 (Processed fruit and vegetable products. Preparation of samples and methods of physico-chemical analysis. Measurements of carotenoid and beta-carotene content).

10. Domaradzki P, Malik A, Wójcik W (2010) The content of $\beta$-carotene and vitamin C in selected carrot products. Chem Toksykol 2: 118-121.

11. Ali I, Aboul-Enein HA (2006) Instrumental methods in metal ion speciation, CRC Press.

12. Igielska-Kalwat J, Gościańska J, Nowak I, (2013) Application of astaxanthin - in cosmetic preparations. Kosmetologia Estetyczna 2: 8386.

13. Igielska-Kalwat J, Wawrzyńczak A, Nowak I, (2012) Carotene as an exemplary carotenoid and its application in cosmetic industry. Chemik $2: 140-144$

14. Igielska-Kalwat J, Gościańska J, Nowak I (2014) Przem Chem 7: 11101140.

15. Mordi RC (1993) Mechanism of $\beta$-carotene degradation. Biochem J 15: 310-315.

16. Boon CS, McClements DJ, Wiess J, Decker EA (2010) Crit Rev Food Sci 50: 515-519.

17. Lee MT, Chen BH (2008) Food Chem 78: 425-430.

18. Kopec RE, Riedel KM, Harrison EH, Curley RW J, Hruszkewycz DP, et al. (2010) Agric Food Chem 58: 3290-3295.

19. Nardo TD, Shiroma-Kian C, Halim Y, Francis D, Rodriquez Saona LE (2009) J Agr Food Chem 57: 1105-1111. 
ISSN: 2574-1241

DOI: 10.26717/BJSTR.2019.13.002355

Joanna Igielska-Kalwat. Biomed J Sci \& Tech Res

(C) (i) This work is licensed under Creative

Submission Link: https://biomedres.us/submit-manuscript.php

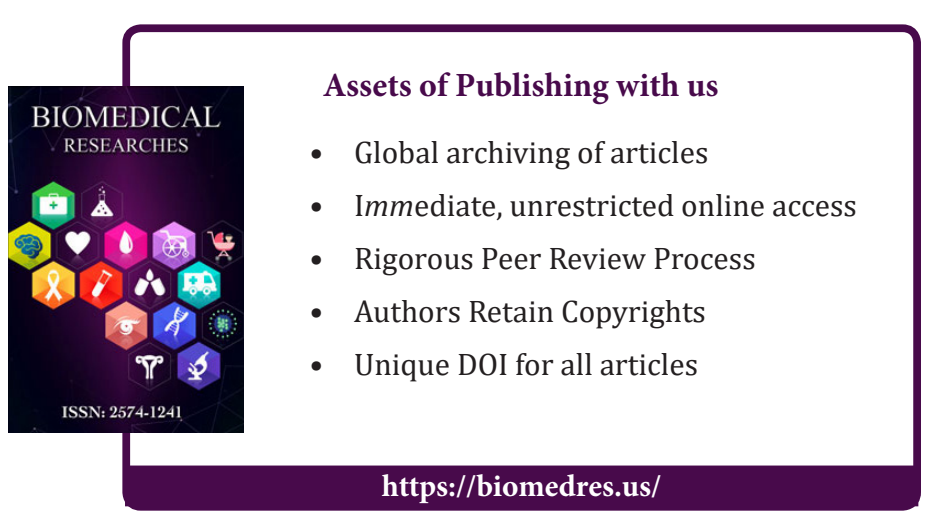

